03,13

\title{
Механизм диффузии монооксидов углерода и кремния в кристалле кубического карбида кремния
}

\author{
(C) С.А. Кукушкин ${ }^{1}$, А.В. Осипов ${ }^{2}$ \\ ${ }^{1}$ Институт проблем машиноведения РАН, \\ Санкт-Петербург, Россия \\ ${ }^{2}$ Санкт-Петербургский национальный исследовательский университет \\ информационных технологий, механики и оптики, \\ Санкт-Петербург, Россия \\ E-mail: sergey.a.kukushkin@gmail.com
}

Поступила в Редакцию 16 июля 2019 г.

В окончательной редакции 16 июля 2019 г.

Принята к публикации 25 июля 2019 г.

\begin{abstract}
Описаны основные процессы, протекающие при диффузии газов монооксидов углерода $\mathrm{CO}$ и кремния $\mathrm{SiO}$ через слой монокристаллического карбида кремния $\mathrm{SiC}$ кубического политипа. Данная задача возникает при выращивании слоя монокристаллического $\mathrm{SiC}$ методом согласованного замещения атомов за счет химической реакции кристаллической подложки кремния с газом СО. Продуктами реакции являются эпитаксиальный слой $\mathrm{SiC}$ и газ $\mathrm{SiO}$. Показано, что молекулы $\mathrm{CO}$ и $\mathrm{SiO}$ распадаются в кристалле $\mathrm{SiC}$ на отдельные атомы. Диффузия атомов кислорода осуществляется по междоузлиям только в направлении [110] с энергией активации $2.6 \mathrm{eV}$. Перемещение атомов $\mathrm{Si}$ и C происходит по вакансионному механизму в соответствующих подрешетках $\mathrm{SiC}$ с энергиями активации $3.6 \mathrm{eV}$ и $3.9 \mathrm{eV}$ соответственно и также лишь в направлении [110].
\end{abstract}

Ключевые слова: карбид кремния, диффузия, ab initio моделирование, эпитаксия.

DOI: $10.21883 /$ FTT.2019.12.48594.50ks

\section{1. Введение}

Получение высококачественных пленок широкозонных полупроводников, таких как карбид кремния ( $\mathrm{SiC})$, нитрид алюминия (AlN), нитрид галлия $(\mathrm{GaN})$, на подложках кремния $(\mathrm{Si})$ является одной из важнейших задач микро- и оптоэлектроники. В работах [1-3] была разработана принципиально новая методика роста таких слоев с использованием промежуточного буферного слоя карбида кремния толщиной 50-150 nm. Сам карбид кремния выращивался из кристалла кремния $(\mathrm{Si})$ методом согласованного замещения атомов за счет химической реакции

$$
2 \mathrm{Si}(\text { crystal })+\mathrm{CO}(\text { gas })=\mathrm{SiC}(\text { crystal })+\mathrm{SiO}(\text { gas }) \uparrow .
$$

Транспорт газа-реагента монооксида углерода $(\mathrm{CO})$ и газа продукта реакции монооксида кремния $(\mathrm{SiO})$ через слой $\mathrm{SiC}$ играет ключевую роль для определения скорости роста $\mathrm{SiC}$. В настоящее время неизвестны ни механизмы диффузии $\mathrm{CO}$ и $\mathrm{SiO}$ через $\mathrm{SiC}$, ни соответствующие значения коэффициентов диффузии, ни энергии активации диффузии. Не известно даже, какая стадия лимитирует скорость роста $\mathrm{SiC}$. Чтобы исследовать эти вопросы в настоящей работе методами $a b$ initio смоделированы все основные процессы транспорта газов СО и $\mathrm{SiO}$ через слой $\mathrm{SiC}$. Для моделирования применялся пакет Medea-Vasp, использующий псевдопотенциалы проекционных присоединенных волн (Projector Augmented
Waves, PAW) [4]. Во всех расчетах использовался метод функционала плотности с базисом плоских волн, а обменно-корреляционная энергия рассчитывалась в рамках приближения мета-функционала SCAN [5], существенным образом уточняющего обобщенно-градиентное приближение (Generalized Gradient Approximation, GGA). Энергия обрезания плоских волн во всех расчетах была равна $400 \mathrm{eV}$.

\section{Ab initio моделирование}

Для моделирования использовалась суперячейка карбида кремния кубического политипа $\mathrm{SiC}-3 \mathrm{C}$, имеющая размеры $8.72 \times 6.17 \times 9.25 \AA$ и состоящая из 48 независимых атомов (рис. 1). Суперячейка была ориентирована так, что ось $x$ направлена по [001], ось $y-$ по [110], ось $z$ - по [110]. Размер суперячейки в направлении [110] специально выбран наибольшим и равным 3 периодам в этом направлении, поскольку основное движение атомов осуществляется именно по [110]. Интегрирование в первой зоне Бриллюэна проводилось по $k$-точкам, выбранным в виде сетки $3 \times 4 \times 3$, полученной с помощью схемы Монхорста-Пака. Исследования показали, что молекулы $\mathrm{CO}$ и $\mathrm{SiO}$, оказавшись внутри кристалла $\mathrm{SiC}$, сразу же распадаются на отдельные атомы, поскольку размер пустот в $\mathrm{SiC}$ слишком мал для них. Атом кислорода, в принципе, может двигаться в разных направлениях, однако энергия активации миграции в 


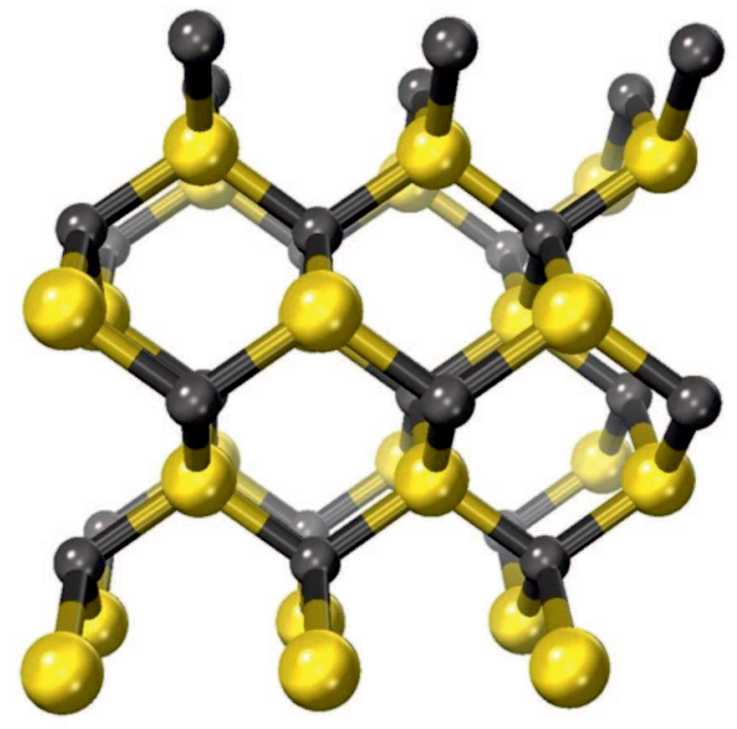

Рис. 1. Суперъячейка карбида кремния $\mathrm{SiC}-3 \mathrm{C}$ из 48 атомов, используемая при $a b$ initio моделировании. Темные шарики атомы C, светлые шарики - атомы Si.

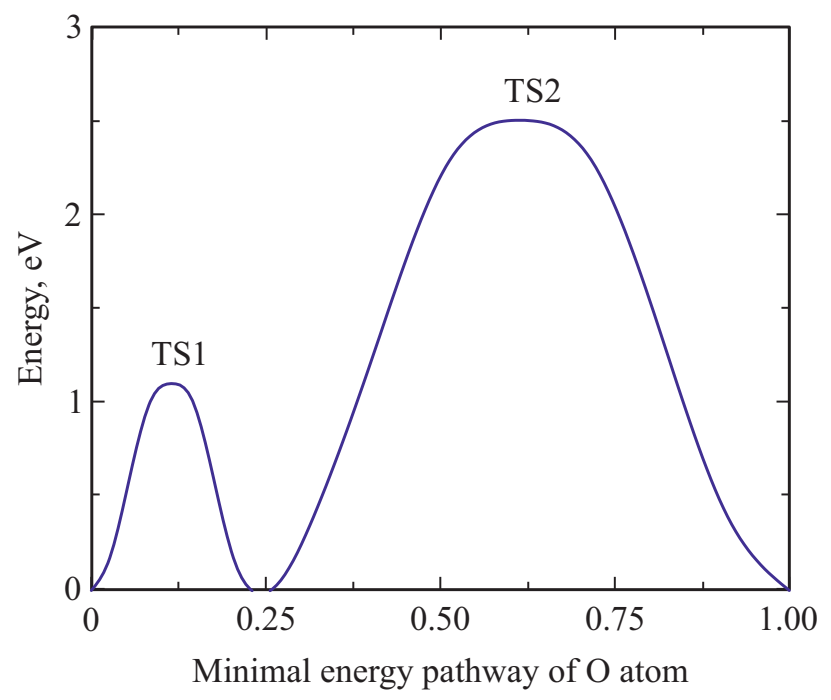

Рис. 2. Энергетический профиль процесса миграции атома кислорода в $\mathrm{SiC}-3 \mathrm{C}$ в направлении [110] на один период решетки. Величина энергетических барьеров, соответствующих двум переходным состояниям TS1 и TS2, равна $1.1 \mathrm{eV}$ и $2.5 \mathrm{eV}$ соответственно.

направлении [110] оказалась значительно меньше, чем в других направлениях. В квантовой химии процесс миграции лучше всего описывается методом упругих подталкивающих связей (Nurged Elastic Bands, NEB) [6]. Идея данного метода заключается в том, что зная начальное и конечное положение атомов, можно заморозить систему и ввести в нее дополнительные силы, которые направят атомы от начального состояния к конечному. Если выполнить определенные условия, то система пойдёт по пути с минимальным перепадом энергии (Minimal
Energy Pathway, MEP) [6]. Это такой путь превращения системы, что любое локальное изменение пути приводит к увеличению энергии системы в окрестности данной точки пути. Иными словами, это путь наискорейшего спуска из исходной конфигурации атомов в конечную конфигурацию, то есть в данном случае наиболее вероятный путь миграции атома. Соответственно, сечение поверхности потенциальной энергии вдоль пути превращения является энергетическим профилем данного процесса. Расчет методом NEB дает энергетический профиль перемещения атома кислорода в кубическом $\mathrm{SiC}$ на один период $3.08 \AA$ в направлении [110], изображенный на рис. 2. Высота активационного барьера для миграции атома О в кубическом $\mathrm{SiC}$ в направлении [110] равна $2.5 \mathrm{eV}$. Для того чтобы силы, действующие на атомы, были меньше $0.05 \AA$, потребовалось 50 итераций при 15 изображениях (images) в методе NEB.

\section{3. Результаты исследования}

Конфигурации атомов, соответствующие исходному, конечному, промежуточному и двум переходным состояниям TS1 и TS2, изображены на рис. 3. Наивысший барьер для миграции атома О соответствует состоянию TS2, в котором атом О образует единственную связь с атомом $\mathrm{Si}$ (рис. 3). Длина данной связи равна $1.58 \AA$, то есть она растянута примерно на $5 \%$, что и обеспечивает барьер миграции. Анализ спектра собственных частот данной конфигурации TS2 показывает, что он содержит единственную отрицательную (мнимую) частоту, равную $-600 \mathrm{~cm}^{-1}$. Это доказывает, что конфигурация TS2 действительно является переходным состоянием в процессе миграции атома О в направлении [110]. В других направлениях энергия активации миграции заметно выше, поэтому наиболее вероятна миграция только в направлении [110], а таких эквивалентных направлений в кристалле $\mathrm{SiC}-3 \mathrm{C}$ всего 6.

Аналогичные расчеты, выполненные методом NEB, показывают, что атомы $\mathrm{Si}$ и C практически не могут мигрировать по междоузлиям $\mathrm{SiC}$, так как энергия миграции превышает $8 \mathrm{eV}$. Поэтому основной механизм миграции этих атомов - вакансионный. Вакансии в подрешетках как $\mathrm{Si}$, так и С имеются при данном механизме синтеза $\mathrm{SiC}$ в достаточно больших количествах по следующим причинам. Во-первых, химическая адсорбция молекулы $\mathrm{CO}$ на изломе ступени $\mathrm{SiC}$ приводит к образованию кремниевой вакансии $V_{\mathrm{Si}}$, которая сразу же начинает мигрировать к границе раздела $\mathrm{SiC} / \mathrm{Si}$, где у нее сток. Во-вторых, замещение атома $\mathrm{Si}$ на атом C в кремнии на границе раздела $\mathrm{SiC} / \mathrm{Si}$ приводит к образованию углеродной вакансии в $\mathrm{SiC}$, поскольку атом C уходит из $\mathrm{SiC}$, а вошедший атом $\mathrm{Si}$ рано или поздно попадет в кремниевую вакансию. Углеродная вакансия мигрирует от границы $\mathrm{SiC} / \mathrm{Si}$ к поверхности $\mathrm{SiC}$, где в нее рано или поздно попадет атом C из молекулы CO. $\mathrm{B}$-третьих, после того как часть атомов $\mathrm{Si}$ в кремнии 


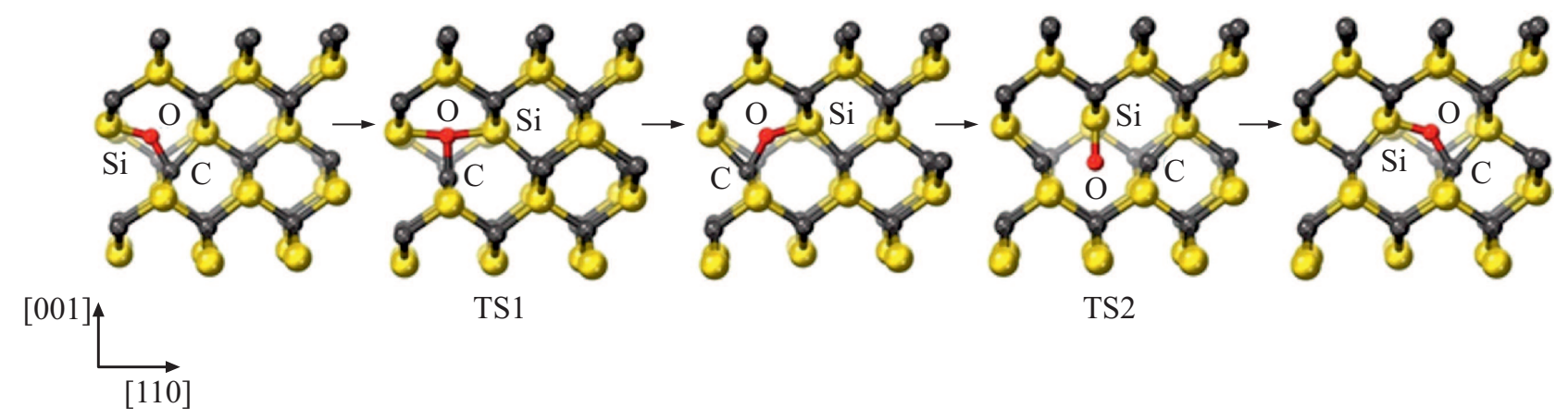

Рис. 3. Геометрическая конфигурация атомов, соответствующая 5 основным состояниям (3 энергетическим минимумам и 2 седловым точкам TS1 и TS2) при миграции атома кислорода в $\mathrm{SiC}-3 \mathrm{C}$ в направлении [110] на один период решетки $3.08 \AA$. Атомы $\mathrm{Si}, \mathrm{C}, \mathrm{O}$ подписаны буквами.

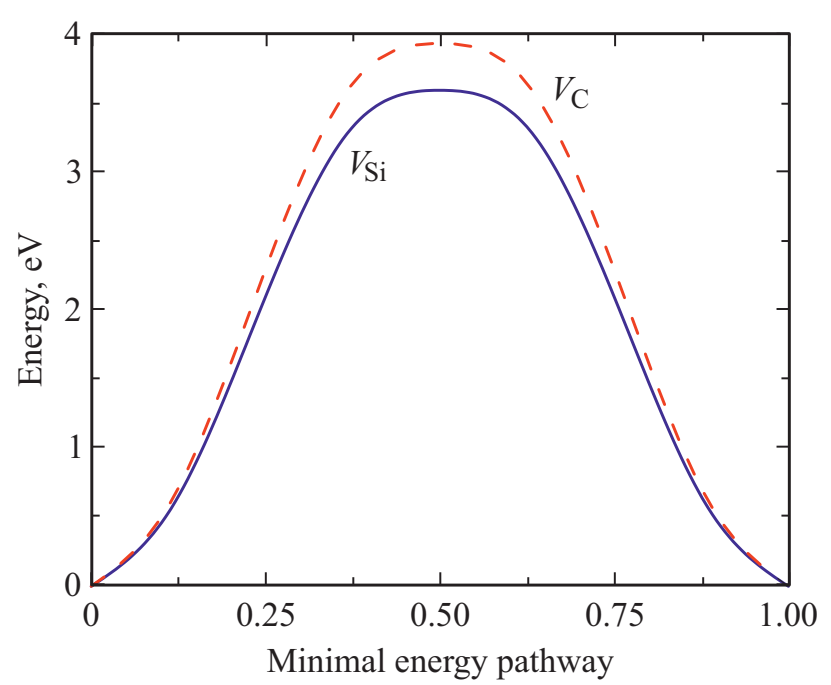

Рис. 4. Энергетический профиль процесса миграции кремниевой $V_{\mathrm{Si}}$ и углеродной $V_{\mathrm{C}}$ вакансий в $\mathrm{SiC}-3 \mathrm{C}$ в направлении [110] на один период решетки. Величины энергетических барьеров для $V_{\mathrm{Si}}$ и $V_{\mathrm{C}}$ равны $3.6 \mathrm{eV}$ и $3.9 \mathrm{eV}$ соответственно.

заместится на С, решетка кремния „схлопнется“, так как объем ячейки $\mathrm{SiC}-3 \mathrm{C}$ в два раза меньше объема ячейки $\mathrm{Si}$. Возникающие при этом в $\mathrm{SiC}$ сильнейшие сжимающие напряжения за счет эффекта восходящей диффузии приводят к образованию дополнительных кремниевых вакансий [7,8]. Кроме того, в работе [9] показано, что кремниевой вакансии выгодно трансформироваться в углеродную вакансию плюс антисайт $C_{\mathrm{Si}}$, то есть атом углерода, находящийся на месте атома кремния. Однако для этого необходимо преодолеть барьер $3.1 \mathrm{eV}$. Антисайт является неподвижной структурой, а углеродная вакансия после превращения продолжает движение к поверхности $\mathrm{SiC}$. Таким образом, существует два газа вакансий, кремниевых $V_{\mathrm{Si}}$ и $V_{\mathrm{C}}$ углеродных, которые взаимодействуют между собой.

Методом NEB были рассчитаны энергетические профили процессов миграции кремниевых и углеродных вакансий в $\mathrm{SiC}-3 \mathrm{C}$ в различных направлениях. Так же как и в случае с атомами O, наименьший барьер миграции оказался в направлении [110]. На рис. 4 показаны зависимости энергии системы от пути с минимальным перепадом энергии МЕР для вакансий $V_{\mathrm{Si}}$ и $V_{\mathrm{C}}$ в направлении [110]. Самый большой энергетический барьер миграции, равный $3.9 \mathrm{eV}$, соответствует миграции углеродной вакансии (рис. 4). Поэтому при низких температурах в чистом $\mathrm{SiC}$ именно углеродные вакансии лимитируют рост пленки $\mathrm{SiC}$ (энергетический барьер самой химической реакции равен $2.6 \mathrm{eV}$ [10]). Однако для легированных материалов, а также при повышении температуры ситуация может измениться. Например, если исходный кремний был легирован бором, то барьер активации миграции кремниевой вакансии может повысится и уже кремниевые вакансии начнут лимитировать процесс роста $\mathrm{SiC}$. Кроме того, при повышении температуры до значений $1100-1200^{\circ} \mathrm{C}$ значительная часть кремниевых вакансий перейдет в углеродные вакансии плюс неподвижные углеродные структуры (антисайты), представляющие собой почти плоский кластер из 4 атомов C (энергия активации этого процесса равна $3.1 \mathrm{eV}$ [9]). В этом случае кремниевые вакансии будут лимитировать рост $\mathrm{SiC}$, поскольку произведение концентрации кремниевых вакансий на их подвижность будет меньше, чем у углеродных вакансий. По-видимому, именно эта ситуация наиболее часто наблюдается на практике, поскольку данные углеродные структуры регистрируются как инфракрасной спектроскопией (они дают новую линию $960 \mathrm{~cm}^{-1}$ ) [11], так и эллипсометрией, которая позволяет измерить их объемную концентрацию [9]. Обычно она оказывается в интервале $1-3 \%$ в зависимости от типа и степени легирования исходного кремния [9]. Если кремниевые вакансии лимитируют рост $\mathrm{SiC}$, то в этом случае продукт реакции $\mathrm{SiO}$ скапливается внутри слоя $\mathrm{SiC}$, оказываясь не в состоянии выйти наружу. Иногда это приводит к микровзрывам слоя $\mathrm{SiC}$, напоминающим извержение вулкана. Такие „извержения“ регулярно регистрируются экспериментально при низких давлениях СО [1]. 
Таким образом, в настоящей работе методами квантовой химии было показано, что вакансии $V_{\mathrm{Si}}$ и $V_{\mathrm{C}}$ играют ключевую роль в кинетике реакции (1). Транспорт газа-регента $\mathrm{CO}$ в зону реакции и газа-продук0та реакции $\mathrm{SiO}$ из зоны реакции осуществляется только в направлении [110] и эквивалентных ему, то есть в направлении каналов $\mathrm{SiC}$. Миграция молекул $\mathrm{CO}$ и $\mathrm{SiO}$ эквивалентна миграции атома $\mathrm{O}$ и вакансий $V_{\mathrm{Si}}$ и $V_{\mathrm{C}}$, поскольку атомам $\mathrm{Si}$ и С мигрировать необязательно, так как атом О легко образует химическую связь с любым атомом кристалла $\mathrm{SiC}$. Энергетический барьер миграции вакансий более чем в 2 раза ниже, чем барьер миграции атомов, и равен в идеальном кристалле $3.6 \mathrm{eV}$ для $V_{\mathrm{Si}}$ и $3.9 \mathrm{eV}$ для $V_{\mathrm{C}}$. Поэтому при низких температурах синтез $\mathrm{SiC}$ лимитируется миграцией $V_{\mathrm{C}}$. В кристалле $\mathrm{SiC}-3 \mathrm{C}$, содержащем границы двойников, барьеры миграции могут быть на 10-20\% ниже. Начиная с температуры $1100-1200^{\circ} \mathrm{C}$ значительная часть кремниевых вакансий перейдет в углеродные вакансии плюс неподвижные углеродные структуры (энергия активации этого процесса равна $3.1 \mathrm{eV}$ ). Поэтому из-за недостатка кремниевых вакансий они могут лимитировать синтез $\mathrm{SiC}$. В этом случае в $\mathrm{SiC}$, синтезированном методом согласованного замещения атомов, будут находиться как углеродные кластеры, так и следы микровзрывов, вызванных скапливанием большого количества $\mathrm{SiO}$ внутри слоя $\mathrm{SiC}$. И то и другое регистрируется экспериментально при низких давлениях $\mathrm{CO}$.

\section{Благодарности}

А.В. Осипов выполнял свою часть работы в рамках проекта РНФ № 19-72-30004.

\section{Конфликт интересов}

Авторы заявляют, что у них нет конфликта интересов.

\section{Список литературы}

[1] S.A. Kukushkin, A.V. Osipov. J. Phys. D.: 47, 313001 (2014).

[2] С.А. Кукушкин, А.В. Осипов, Н.А. Феоктистов. ФТТ 56, 1457 (2014).

[3] Ш.Ш. Шарофидинов, С.А. Кукушкин, А.В. Редьков, А.С. Гращенко, А.В. Осипов. ПЖТФ 45, 24 (2019).

[4] J. Hafner. J. Comp. Chem. 29, 2044 (2008).

[5] J. Sun, A. Ruzsinszky, J.P. Perdew. Phys. Rev. Lett. 115, 036402 (2015).

[6] K.J. Caspersen, E.A. Carter. PNAS 102, 6738 (2005).

[7] С.А. Кукушкин, А.В Осипов. ПЖТФ 43 (13), 81 (2017).

[8] A.V. Osipov. J. Phys. D: 28, 1670 (1995).

[9] С.А. Кукушкин, А.В. Осипов. ФТТ 60, 1841 (2018).

[10] S.A. Kukushkin, A.V. Osipov. J. Phys. D.: 50, 464006 (2017).

[11] С.А. Грудинкин, С.А. Кукушкин, А.В. Осипов, Н.А. Феоктистов. ФТТ 59, 2403 (2017).

Редактор Ю.Э. Китаев 